\title{
ANTIFUNGAL EFFECTIVENESS OF VIRGIN COCONUT OIL MOUSSE AGAINST CANDIDA ALBICANS BIOFILM IN CHILDREN WITH EARLY CHILDHOOD CARIES
}

\author{
Monica Monica', Eva Fauziah'², Sarworini Bagio Budiardjo², Margaretha Suharsini², Heriandi Sutadi², Ike Siti Indiarti², \\ Mochamad Fahlevi Rizal²
}

'Pediatric Dentistry Residency Program, Faculty of Dentistry, Universitas Indonesia Jakarta, Indonesia

2Lecturer in the Pediatric Dentistry Department, Faculty of Dentistry, Universitas Indonesia Jakarta, Indonesia

\begin{abstract}
InTRODUCTION: Early childhood caries is defined as the presence of one or more decayed teeth, missing (due to caries) or filled teeth surface in a child 71 months of age or younger. The presence of Candida albicans will increase caries pathogenicity.

ОвјестіVEs: The objective of this study was to analyze the antifungal effectiveness of virgin coconut oil (VCO) mousse against viability of C. albicans biofilm in children with early childhood caries.

MATERIAL AND METHODS: In this experimental laboratory study, C. albicans biofilm was exposed to three concentrations of VCO mousse, namely $0.8 \%, 8 \%$ and $80 \%$. C. albicans biofilm viability was tested using crystal violet $0.5 \%$ and a colony forming unit assay. Statistical analysis was conducted using 1-way ANOVA.

RESULTS: VCO mousse $80 \%$ showed optical density and total viable colony count (CFU/ml) values significantly different compared to VCO mousse $0.8 \%$ and $8 \%(p<0.05)$.

Conclusions: VCO mousse exhibited antifungal effect against viability of $C$. albicans biofilm in children with early childhood caries.
\end{abstract}

KEY WORDS: virgin coconut oil, Candida albicans, early childhood caries.

J Stoma 2018; 71, 3: 259-262

DOI: https://doi.org/10.5114/jos.2018.80643

\section{INTRODUCTION}

Dental caries is a complex disease that has multiple contributing factors [1]. One destructive form of tooth decay that commonly affects young children is early childhood caries (ECC) [2]. ECC is defined as the presence of one or more decayed teeth, missing (due to caries) or filled teeth surface in a child 71 months of age or younger $[3,4]$. ECC is an infectious disease which depends on biofilm [5]. Biofilm will develop when bacteria interact with dietary sugar and accumulate on the tooth surface forming microcolonies or densely packed cell clusters [6].

Candida is a normal commensal in the oral cavity of healthy individuals [2, 7]. In healthy individuals, the percentage of Candida colonization ranges from $20 \%$ to $40 \%$. The most prevalent Candida in the oral cavity is C. albicans. The presence of C. albicans will increase caries pathogenicity [2]. De Carvalho and Molaic reported that children with ECC have a greater quanti-
JOURNAL OF
STOMATOLOGY

『PTSP
ADDRESS FOR CORRESPONDENCE: Eva FauZiah,

Department of Pediatric Dentistry, Universitas Indonesia, Jakarta 10430,

Indonesia, Jl. Salemba Raya no. 4, Jakarta, Indonesia,

e-mail: eva.fauziah@ui.ac.id 
ty of C. albicans in dental plaque, infected dentin and saliva compared to caries-free children [7]. C. albicans could adhere and dissolve hydroxyapatite approximately 20-fold higher compared to Streptococcus mutans [3].

One of the natural coconut products without heating and chemical processing is virgin coconut oil (VCO) $[8,9]$. The majority component of VCO is $93 \%$ saturated fats with $47-53 \%$ being medium chain fatty acids [10, 11]. Therefore, VCO exhibits antifungal, antibacterial and antivirus activity [10]. One form of ECC prevention is applying tooth mousse [12].

\section{OBJECTIVES}

The present study aimed to analyze the antifungal effectiveness of VCO mousse against C. albicans in ECC.

\section{MATERIAL AND METHODS}

This study was approved by the Ethics Committee of the Faculty of Dentistry, Universitas Indonesia. This was an experimental laboratory study. The inclusion criteria were child age in the range 3-5 years, deciduous dentition, deft index score $\geq 5$ and no systemic disease. The exclusion criteria were child above 5 years, caries free, medically compromised, received antibiotics treatment in the past 1 month, major and minor salivary gland disease and radiotherapy. Subjects were included in the study after informed consent was obtained. A plaque sample was swabbed from all tooth surfaces using a sterile toothpick and inserted into $1 \mathrm{ml}$ Sabouraud dextrose broth (SDB) in an Eppendorf tube. The tube was kept in a $4^{\circ} \mathrm{C}$ cooler box. This study was conducted in the Oral Biology Laboratory of Universitas Indonesia. The antifungal effectiveness of VCO mousse extract against C. albicans was assessed using a crystal violet test and colony count $(\mathrm{CFU} / \mathrm{ml})$.

\section{LABORATORY}

The plaque sample was centrifuged then removed from supernatant and $100 \mu \mathrm{l}$ of saline was added to precipitate. After vortexing, a $10 \mu \mathrm{l}$ suspension was transferred into CHROMagar by the streak-plate method and incubated for 48 hours at $37^{\circ} \mathrm{C}$. As a result, a C. albicans colony will exhibit a green color. A colony of C. albicans was extracted from the CHROMagar and placed into SDB. The broth was incubated for 24 hours at $37^{\circ} \mathrm{C}$. After incubation, a DNA sample was identified using polymerase chain reaction (Dreamtaq Green PCR Master Mix) technique. This step was taken to ensure that the sample was C. albicans. After PCR, C. albicans was diluted in SDB medium and incubated for 24 hours. A laboratory strain of C. albicans (ATCC 10321) was also tested in this research.
The VCO used in this research has been certified by the Indonesian government (Depkes P-IRT No. 207340101143). The VCO was processed to mousse by Akademi Farmasi IKIFA. Three VCO mousse concentrations were tested in this research, which were $0.8 \%, 8 \%$ and $80 \%$.

A C. albicans biofilm was obtained by placing $100 \mu \mathrm{l}$ of diluted Candida (clinical and laboratory) into a 96-microwell plate. The microwell was incubated for 24 hours. After incubation, microwell content was removed by blotting with paper towels. Nonadherent cells were removed by thoroughly washing biofilm with $100 \mu$ sterile PBS and $50 \mu \mathrm{l}$ of SDB was added to the microwell. Another $100 \mu \mathrm{l}$ of VCO mousse $(0.8 \%, 8 \%, 80 \%)$ was placed into the microwell (duplo). Positive and negative controls in this research respectively were CPP-ACP and SDB (duplo). Two 96-microwell plates were incubated for both crystal violet and colony forming unit assay.

\section{CRYSTAL VIOLET TEST}

After incubation, microwell content was removed by blotting with paper towels and thoroughly washed twice with $100 \mu \mathrm{l}$ of sterile PBS. Crystal violet $0.5 \%(200 \mu \mathrm{l})$ was inserted into each well using a micropipette. After 15 minutes at room temperature, the microwell was washed in $100 \mu \mathrm{l}$ of PBS sterile. C. albicans biofilm viability (optical density) was measured in a microplate reader at $490 \mathrm{~nm}$.

\section{COLONY FORMING UNIT ASSAY}

Following antifungal challenge and subsequent washing, sessile cells were removed from the plate by scraping with a sterile micropipette. The sessile cells were added to sterile PBS and vortexed for $30 \mathrm{~s}$. Each sample was diluted in sterile PBS and dispensed onto Sabouraud Dextrose Agar plates. Plates were incubated for $24 \mathrm{~h}$ at $37^{\circ} \mathrm{C}$. Colonies were counted the following day to estimate the total viable colony counts from each plate $(\mathrm{CFU} / \mathrm{ml})$.

\section{STATISTICAL ANALYSIS}

Statistical analyses were performed using SPSS 20.00 (SPSS, Chicago, IL, USA). The Shapiro-Wilk test was used to assess the normality of variables. After descriptive analysis, the comparisons between variables for optical density (OD) value and viable cell counts were analyzed using the 1-way ANOVA test. The statistical level of significance was set at 95\% $(p<0.05)$.

\section{RESULTS}

Table 1 presents distribution data of optical density (OD) value and viable colony counts $(\mathrm{CFU} / \mathrm{ml})$. Based 
on the Shapiro-Wilk test, distribution data for both values were normal $(p>0.05)$. Each group of $C$. albicans biofilm viability was compared against one another by the parametric test 1-way ANOVA.

Figure 1 shows a comparison of optical density values between different groups using a 1-way ANOVA test. The difference between the groups was statistically significant $(p<0.001)$. It was found that the mean optical density for VCO mousse $80 \%$ was 0.110 , whereas values for $0.8 \%, 8 \%$ and base respectively were $0.247,0.248$, 0.255 . The difference between the groups was significant $(p<0.001)$. On the other hand, the comparison between VCO mousse $80 \%$ and CPP-ACP was not significantly different ( $p$ value 1.000). A similar outcome was also found for the comparison between VCO mousse $80 \%$ and the negative control ( $p$ value 0.184 ).

Figure 2 presents a comparison of total viable colony counts $(\mathrm{CFU} / \mathrm{ml})$ between different groups using the 1-way ANOVA test. The difference between the groups was statistically significant $(p<0.001)$. It was found that the mean colony count for VCO mousse $80 \%$ was 20.75 , whereas for $0.8 \%, 8 \%$, base and negative control the counts were $525.75,515.75,561.25$, 567 respectively. The difference between the groups was significant $(p<0.001)$. On the other hand, the comparison between VCO mousse $80 \%$ and CPP-ACP was not significantly different ( $p$ value 0.573 ).

\section{DISCUSSION}

Almost $36 \%$ of the world population has experienced dental caries and about $9 \%$ of the infant population is affected [13]. The most common caries found in young children is ECC, previously known as nursing caries or baby bottle caries [14]. Dental caries is associated with the ecological oral environment, infectious bacteria and dietary sugar [15]. The crucial carious process is local enamel demineralization resulting in degradation of hydroxyapatites. This process takes place within bacterial biofilm or dental plaque that covers the tooth surface. Caries lesions will develop when oral biofilms mature and remain on the tooth surface for a long period [13].

Several studies showed that Candida has a role in microbial attachment to the tooth surface. In vitro study showed that Candida enhanced Streptococcus mutans adherence to the oral biofilm. Therefore, one caries etiology is C. albicans. C. albicans participates in biofilm formation and has the ability to ferment glucose and maltose, producing acid and gas $[3,16]$. De Carvalho et al. reported that in biofilm of ECC C. albicans is twice as prevalent as in caries-free children [7]

Coconut products such as coconut oil have been used as diet and traditional medicine in Asian culture. One of the purest forms of coconut oil is VCO. Several reports suggested that VCO has antifungal, antibacterial,
TABLE 1. Shapiro-Wilk test for optical density and colony count (CFU/ml) value

\begin{tabular}{|c|c|c|c|}
\hline \multicolumn{1}{|c}{ Group } & \multicolumn{3}{c|}{ Shapiro-Wilk test $(\boldsymbol{p})$} \\
Optical density & CFU/ml \\
\hline VCO mousse 0.8\% & 4 & 0.900 & 0.613 \\
\hline VCO mousse 8\% & 4 & 0.517 & 0.970 \\
\hline VCO mousse 80\% & 4 & 0.955 & 0.976 \\
\hline Mousse base & 4 & 0.492 & 0.798 \\
\hline Positive control (CPP-ACP) & 4 & 0.180 & 0.213 \\
\hline Negative control & 4 & 0.492 & 0.288 \\
\hline
\end{tabular}

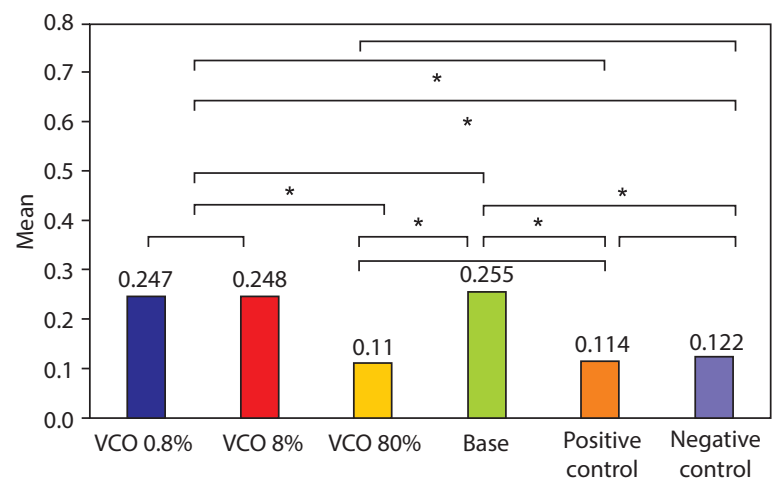

FIGURE 1. Bar graphs of post-hoc tests for optical density values between groups

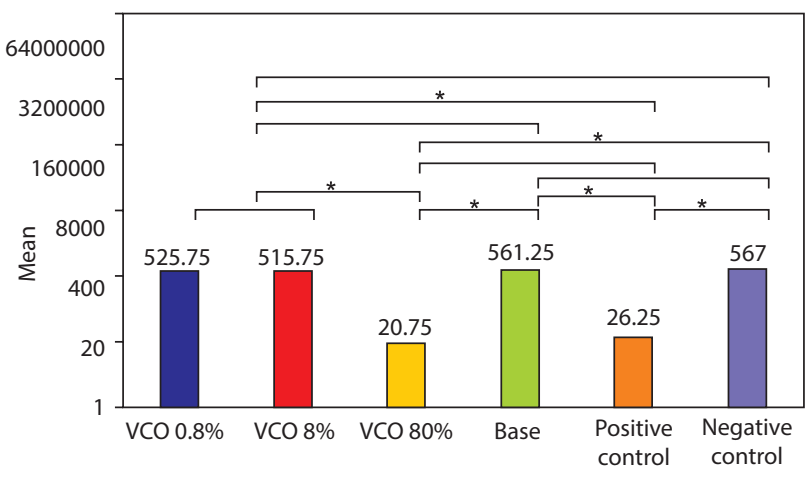

FIGURE 2. Bar graphs of post-hoc tests for colony count between groups

antiviral and antioxidant properties [17]. VCO has antimicrobial activity against Candida albicans, Staphylococcus aureus, Streptococcus mutans, Actinomyces spp., Prevotella spp. and Cytomegalovirus [8, 18, 19]. In this study, the optical density value of VCO mousse $80 \%$ showed no statistically significant difference compared to the negative control. The possible cause of this outcome was the cloudy ingredients of mousse such as $\mathrm{Na}-\mathrm{CMC}$, sodium saccharin, guar gum, titanium dioxide, glycerol, zinc oxide, propylene glycol, D-sorbitol, Aquades, sodium benzoate, phosphoric acid and xylitol. A similar result was also found in the CPP-ACP group 
compared to the negative control. However, based on viable colony counts the difference of both VCO mousse $80 \%$ and CPP-ACP was statistically significant compared to the negative control. Therefore, VCO mousse was proven to possess antifungal ability against $C$. albicans biofilm. Among three concentrations of VCO mousse which were tested, VCO mousse $80 \%$ showed the most effective antifungal action. The Yusof et al. study showed that the minimum VCO extract concentration that exhibits C. albicans colony inhibition was $50 \%$. The duration of extract exposure to C. albicans was $24 \mathrm{~h} \mathrm{[10].}$

VCO has many medical effects due to the high percentage of medium chain fatty acids (MCFA) [10, 17]. Several fatty acids have the highest antifungal activities, such as lauric acid, capric acid, monoglyceride monolaurin and monocaprin $[8,10,17,20]$. The mechanism action of lauric acid against Candida is initiated by entering the lipid bilayer of fungal membranes and physically disturbing the fungal cell membrane, resulting in cell membrane disorganization due to increased fluidity of the membrane. This will lead to cell membrane destruction of $C$. albicans then intracellular components leakage, cytoplasmic disorder and protoplasmic lysis. As a result, C. albicans colony growth is inhibited [10, 17].

Other fatty acids that exhibit antifungal effect are capric acid, caprylic acid and myristic acid [8, 10]. Capric acid has been reported to be the fastest and most effective fatty acid eliminating C. albicans. This fatty acid inhibits $C$. albicans filamentation, and reduces biofilm formation and candidal adhesion, resulting in reducing candidal pathogenicity [17].

\section{CONCLUSIONS}

VCO mousse extract exhibited an antifungal effect against viability of $C$. albicans biofilm from clinical isolates of ECC dental plaque.

VCO mousse $80 \%$ showed no significant difference compared to tooth mousse (CPP-ACP), which was the gold standard in ECC prevention treatment.

Based on the optical density value and colony forming unit assay, VCO mousse with $80 \%$ concentration was proven to reduce $C$. albicans biofilm viability.

\section{ACKNOWLEDGEMENT}

This work is supported by Hibah PITTA 2018 funded by DRPM Universitas Indonesia No. 2154/UN2.R3.1/ HKP.05.00/2018.

\section{CONFLICT OF INTEREST}

The authors declare no potential conflicts of interest with respect to the research, authorship, and/or publication of this article.

\section{References}

1. Farooq I, Moheet IA. A review of novel dental caries preventive material: casein phosphopeptide - amorphous calcium phosphate (CPP-ACP) complex. King Saud Univ J Dent Sci 2013, 4: 47-51.

2. Beena MS, Peedikayil FC, GufranAfmed MB, et al. Comparison of Candida species isolated from children with and without early childhood caries: a descriptive cross-sectional study. J Indian Soc Pedod Prev Dent 2017; 35: 296-300.

3. Ghasempour M, Sefidgar A, Eyzadian H, Gharakhani S. Prevalence of Candida albicans in dental plaque and caries lesion of early childhood caries (ECC) according to sampling site. Casp J Intern Med 2011; 2: 304-308.

4. El Mehdi H, Hind R, Hakima C. The benefits of casein phosphopeptid-amorphous calcium phosphate (CPP-ACP) in pediatric dentistry. Sch J Dent Sci 2016; 3: 247-250.

5. Farhanaz F, Yashoda R, Kalayadhav ML, Manjunath P. Association between Streptococcus mutans and Candida albicans among 3-5-year-old children with early childhood caries: a cross-sectional study. J Indian Assoc Public Health Dentistry 2017; 15: 205-209.

6. Kim D, Sengupta A, Niepa THR, et al. Candida albicans stimulates Streptococcus mutans microcolony development via cross-kingdom biofilm-derived metabolites. Sci Rep 2017; 7: 41332.

7. Thomas A, Mhambrey S, Chokshi K, et al. Association of oral Candida albicans with severe early childhood caries - a pilot study. J Clin Diagnostic Res 2016; 10: 109-112.

8. Burhannuddin Burhannuddin, Karta IW, Tresnanda B, et al. Daya hambat virgin coconut oil terhadap pertumbuhan jamur Candida albicans yang diisolasi dari sampel swab vagina. J Sains dan Teknol 2017; 6: 209-219.

9. Suryani, Dharma A, Manjang Y, et al. Antimicrobial and antifungal activity of lactic acid bacteria isolated from coconut milk fermentation. Res J Pharm Biol Chem Sci 2014; 5: 1587-1595.

10. Yusof NA, Jularso E, Sumaryono B. Efektifitas pemberian virgin coconut oil (OIL) terhadap pertumbuhan Candida albicans growth of Candida albicans. Oral Maxillofac Pathol J 2014; 1: 1-5.

11. Nagase S, Matsue M, Mori Y, et al. Comparison of the antimicrobial spectrum and mechanisms of organic virgin coconut oil and lauric acid against bacteria. J Wellness Heal Care 2017; 41: 87-95.

12. Al-Batayneh OB. Evidence-based recommendations. Smile Dent J 2009; 4: 1-4.

13. Karpiński TM, Szkaradkiewicz AK. Microbiology of dental caries. J Biol Earth Sci 2013; 3: 21-24.

14. Kargul B, Durmus B, Bekiroglu N. Effect of CPP-ACP on remineralisation of early caries lesions in rimary teeth. OHDM 2017; 16 : $1-4$.

15. Daboor SM, Syed F, Masood S. A review on Streptococcus mutans with its diseases dental caries, dental plaque and endocarditis. Indian J Microbiol Res 2015; 2: 76-82.

16. Sofia C. Candida spp. and its role in dental caries. Porto 2012.

17. Tjin LD, Setiawan AS, Rachmawati E. Exposure time of virgin coconut oil against oral Candida albicans. Padjadjaran J Dent 2016; 28: 89-94.

18. Yunarti E. Uji daya hambat virgin coconut oil (VCO) terhadap pertumbuhan Candida albicans secara in vitro. J Sainstek 2010; 2: 156-160.

19. Gayatri A, Fauziah EVA, Suharsini M. Antibacterial effect of virgin coconut oil on the viability of chromogenic bacteria that causes dental black stain in children. Int J Appl Pharm 2017; 9: 83-86.

20. Lavine P, Fauziah E, Rizzal MF, Budiardjo SB. Antibacterial effect of virgin coconut oil on (Actinomyces sp.) that causes dental black stain in children. Asian J Pharm Clin Res 2018; 11: 333-335. 